(19) Benson, G. C.: Klyohara, O. J. Chem. Thermodn. 1979, 11, 1061

(20) Acree, Jr. E. W. J. Chem. Eng. Data. 1983, 28, 215.

(21) Desnoyers, J. E.; Qulrion, F.; Hetu, D.; Perron, G. Can . J. Chem. Eng $1983,61,672$

(22) Desnoyers, J. E.; Beaudoin, R.; Perron, G.; Roux, G. ACS Symp. Ser. 1978, No. 90

(23) Kell, G. C. J. Chem. Eng. Data 1975, 20, 97

(24) Roux, G.; Perron, G.; Desnoyers, J. E. J. Solution Chem. 1978, 7 , 639.

(25) International Critical Tables; McGraw-Hill: New York, 1926.

(26) Fortier, J. L.; Benson, G. C.; Plcker, P. J. Chem. Thermodyn. 1976 $8,289$.

(27) Zlochower, I. A.; Schulman, J. H. J. Colloid Interface Sci. 1967, 24 115.

(28) Gillberg, G.; Lehtinen, H.; Friberg, S. J. Collold Interface Scl. 1970. 40,33
(29) Shah, D. O.; Hamlin, Jr. R. M. Science 1971, 171, 483.

(30) Hansen, J. R. J. Phys. Chem. 1974, 78, 256.

(31) Desroslers, O.; Van Dinter, T.; Saunders, J. K. Can. J. Chem. 1984, 62,56 .

Received for review July 15, 1986. Accepted March 6, 1987. We thank the Government of Canada and the Covernment of Saskatchewan for thet financial support of this project under the Canada-Saskatchewan Heavy Oil Fossil Fuel Agreement. N.P.R. thanks Sri Venkateswara University for allowing a leave of absence to perform this work.

Supplementary Material Avallable: Tables of ultrasonic velocity, density, compressibility, and apparent molar properties for various systems ( 15 pages). Ordering information is given on any current masthead page.

\title{
Solubility of Anthracene in Binary Solvent Mixtures Containing Dibutyl Ether
}

\author{
Mary V. Marthandan and WIIllam E. Acree, Jr.* \\ Department of Chemistry, Kent State University, Kent, Ohio 44242
}

Experimental solubllitles are reported for anthracene in blnary solvent mixtures contalning dibutyl ether with $n$-hexane, cyclohexane, $n$-heptane, methylcyclohexane, $n$-octane, isooctane, and cyclooctane at $25^{\circ} \mathrm{C}$. Results of these measurements, comblned with estimates for the excess Gibbs free energles of the binary solvents, are used to test predictive expressions derived from the nearly Ideal binary solvent (NIBS) model. Expressions based on a volume fraction average of solute propertles in the two pure solvents predict anthracene solubilitles to within a maximum deviation of $5.1 \%$ and an overall average deviation of $2.1 \%$.

\section{Introduction}

This work continues (1-8) a systematic search for mixing models and equations which will provide predictions for thermochemical properties of a solute at high dilution in binary solvent mixtures. In two earller papers, Acree and Rytting (5, 6) reported solubilities for benzil and $p$-benzoquinone in binary solvent mixtures containing carbon tetrachloride, in which the mole fraction solubility of benzil and $p$-benzoquinone cover a 14-fold and 6-fold range, respectively. The experimental data were interpreted with solution models developed previously for solubility in systems containing specific solute-solvent interactions and with models of purely nonspecific solute-solvent interactions and with models of purely nonspecific interactions. A stoichiometric complexation model based entirely on speciflc interactions (nonspeclfic interactions ignored) required several equillbrium constants to mathematically describe the experimental results, while the nearly ideal binary solvent (NIBS) model based on nonspecific interactions described adequately the observed solubilities without introducing a single equilibrium constant.

The success of the NIBS approach in predicting the binary solvent effect on benzil and $p$-benzoquinone solubilities suggested the possibility that this solution model may provide a foundation for approximations of physical interactions even in a system known to contain chemical interactions. To pursue this idea further, the basic NIBS model was extended to systems containing association between the solute (component $A$ ) and a complexing cosolvent (component $\mathrm{C}$ )

$$
\begin{aligned}
& A_{1}+C_{1} \rightleftharpoons A C \\
& K_{A C}{ }^{\phi}=\frac{\phi_{A C}}{\phi_{A_{1}} \phi_{C_{1}}}
\end{aligned}
$$

A relatively simple expression was developed (8) for the determination of solute-solvent equillbrium constants from the measured solubility as a function of solvent composition and the excess Gibbs free energy of the binary solvent mixture

$$
\begin{array}{r}
R T\left[\begin{array}{l}
\ln \left(a_{A}{ }^{\text {solid }} / \phi_{A_{1}}{ }^{\text {sat }}\right)-1+\bar{V}_{A}\left(\frac{\phi_{A_{1}}{ }^{\text {sat }}}{\bar{V}_{A}}+\frac{\phi_{B}}{\bar{V}_{B}}+\right. \\
\left.\left.\frac{\phi_{C}}{\bar{V}_{C}}\right)\right]=\left(1-\phi_{A}{ }^{\text {sat }}\right)^{2}\left[\phi_{B}{ }^{0}\left(\Delta \bar{G}_{A}{ }^{m}\right)_{B}{ }^{*}+\phi_{C}{ }^{0}\left(\Delta \bar{G}_{A}{ }^{m}\right)_{C}{ }^{*}-\right. \\
\left.\bar{V}_{A}\left(X_{B}{ }^{0} \bar{V}_{B}+x_{C}{ }^{0} \bar{V}_{C}\right)^{-1} \Delta \bar{G}_{B C}{ }^{\text {th }}\right]
\end{array}\right.
\end{array}
$$

with the overall volume fraction solubility, $\phi_{A}{ }^{\text {sat }}$, being related to the solubility of the uncomplexed solute and the equilibrium constant by

$$
\phi_{A}{ }^{\text {sat }}=\phi_{A_{1}}{ }^{\text {sat }}\left[1+\bar{V}_{A} K_{A C}{ }^{\phi} \phi_{C_{1}} /\left(\bar{V}_{A}+\bar{V}_{C}\right)\right]
$$

and the quantities $\left(\Delta \bar{G}_{A}{ }^{(h)}\right)_{B}{ }^{*}$ and $\left(\Delta \bar{G}_{A}{ }^{m}\right)_{C}{ }^{*}$ being calculated from the appropriate binary reduction of eq 1

$$
\begin{aligned}
& \left(\Delta \bar{G}_{A}{ }^{\text {th }}\right)_{B}{ }^{*}= \\
& \left(1-\phi_{A}^{\text {sat }-2} R T\left[\ln \left(a_{A}^{\text {sold }} / \phi_{A}^{\text {sat }}\right)-\left(1-\phi_{A}^{\text {sat }}\right)\left(1-\frac{\bar{V}_{A}}{\bar{V}_{B}}\right)\right]\right. \\
& \left(\Delta \bar{G}_{A}^{\text {fh }}\right)_{C}{ }^{*}=\left(1-\phi_{A}^{\text {sat }}\right)^{-2} R T\left[\ln \left(a_{A}^{\text {solld }} / \phi_{A_{1}}^{\text {sat }}\right)-1+\right. \\
& \left.\bar{V}_{\mathrm{A}}\left(\frac{\phi_{\mathrm{A}_{1}}{ }^{\text {sat }}}{\bar{V}_{\mathrm{A}}}+\frac{\phi_{\mathrm{C}}}{\bar{V}_{\mathrm{C}}}\right)\right]
\end{aligned}
$$

using the molar volumes of the pure components, $\bar{V}_{1}$, and the solubilities in the two pure solvents. The superscript $(0)$ denotes that the solvent compositions are calculated as if the solute were not present.

Postulating the formation of a 1:1 anthracene-benzene complex, the authors demonstrated that eq 1 could describe 
the solubility of anthracene in benzene $+n$-heptane and benzene + isooctane mixtures to within a maximum deviation of $4 \%$ using a single value of $K_{A C}{ }^{\phi}=1.91$. More importantly, it was noted that the determination of solute-solvent equilibrium constants from solubility measurements does depend on the manner in which nonspecific interactions are incorporated into the model. In the case of anthracene solubilities, failure to include nonspecific interactions led to a calculated value of $K_{\mathrm{AC}}{ }^{\phi}$ $=4.07$ for the anthracene-benzene complex in solvent mixtures containing $n$-heptane.

Application of eq 1 to solubility measurements does require a prior knowledge of $\Delta \bar{G}_{\mathrm{BC}}{ }^{\text {th }}$, which for many systems may not be easily measurable or readily available in the chemical literature. In anticipation of calculating solute-dibutyl ether association constants from solubility measurements, we decided to first measure anthracene solubilities in several binary solvent mixtures containing dibutyl ether in hopes of estimating $\Delta \bar{G}_{\mathrm{BC}}{ }^{\text {m }}$ values for subsequent studies. Solubilities are reported for anthracene in binary dibutyl ether $+n$-hexane, dibutyl ether + cyclohexane, dibutyl ether $+n$-heptane, dibutyl ether + methylcyclohexane, dibutyl ether $+n$-octane, dibutyl ether + isooctane, and dibutyl ether + cyclooctane mixtures at $25^{\circ} \mathrm{C}$. Results of these measurements, combined with estimated $\Delta \bar{G}_{\mathrm{BC}}{ }^{\text {th }}$ (or $\Delta \bar{G}_{\mathrm{BC}}{ }^{\mathrm{ex}}$ ) values, are compared to predictions based on the NIBS model.

\section{Experimental Section}

Anthracene (Aldrich Gold Label) was used as received. Cyclohexane (Aldrich HPLC), $n$-heptane (Aldrich HPLC), $n$-hexane (Aldrich $99 \%$ ), isooctane (Fisher $99 \mathrm{~mol} \%$ ), n-octane (Aldrich Gold Label), methylcyclohexane (Aldrich Gold Label), cyclooctane (Aldrich Gold Label), and di- $n$-butyl ether (Aldrich Gold Label) were stored over molecular sieves to remove trace water. Binary solvent mixtures were prepared by weight so that compositions could be calculated to 0.0001 mole fraction.

Excess solute and solvent were placed in amber glass bottles and allowed to equilibrate in a constant temperature bath at $25.0^{\circ} \mathrm{C}$ for several days. Attainment of equillbrium was verified by repetitive measurements after several additional days and in some instances by approaching equilibrium from supersaturation by preequilibrating the solution at a higher temperature. Aliquots of saturated anthracene solutions were transferred through a coarse filter into a tared volumetric flask to determine the amount of sample and diluted quantitatively with methanol. Concentrations were determined spectrophotometrically at 356 $\mathrm{nm}$ on a Bausch and Lomb Spectronic 2000. Experimental solubilities of anthracene in the seven binary solvent systems studied are listed in Table I. Numerical values represent the average of between 4 and 8 independent determinations, with the measurements being reproducible to within $\pm 1 \%$.

\section{Results and Discussion}

The general NIBS expressions for predicting solubilities in systems of nonspecific interactions depend on two different models of solution ideality:

$$
\begin{aligned}
& R T \ln \left(a_{A}^{\text {solld }} / X_{A}^{\text {sat }}\right)= \\
& \left(1-X_{A}{ }^{\text {sat }}\right)^{2}\left[X_{B}{ }^{0}\left(\Delta \bar{G}_{A}{ }^{e x}\right)_{B}{ }^{*}+X_{C}{ }^{0}\left(\Delta \bar{G}_{A}{ }^{e x}\right)_{C}{ }^{*}-\Delta \bar{G}_{B C}{ }^{e x}\right] \\
& R T \ln \left(a_{A}^{\text {solld }} / X_{A}^{\text {sat }}\right)=\left(1-\phi_{A}^{\text {sat }}\right)^{2}\left[\phi_{B}{ }^{0}\left(\Delta \bar{G}_{A}{ }^{\text {ex }}\right)_{B}{ }^{*}+\right. \\
& \left.\phi_{C}{ }^{0}\left(\Delta \bar{G}_{A}{ }^{e x}\right)_{C}{ }^{*}-\bar{V}_{A}\left(X_{B}{ }^{0} \bar{V}_{B}+X_{C}{ }^{0} \bar{V}_{C}\right)^{-1} \Delta \bar{G}_{B C}{ }^{e x}\right] \\
& R T\left[\ln \left(a_{A}^{\text {solid }} / \phi_{A}^{\text {sat }}\right)-\left(1-\phi_{A}^{\text {sat }}\right) \times\right. \\
& \left.\left(1-\frac{\bar{V}_{A}}{X_{B}{ }^{0} \bar{V}_{B}+x_{C}{ }^{0} \bar{V}_{C}}\right)\right]=\left(1-\phi_{A}{ }^{\text {sat }}\right)^{2}\left[\phi_{B}{ }^{0}\left(\Delta \bar{G}_{A}{ }^{\text {th }}\right)_{B}^{*}+\right. \\
& \left.\phi_{C}{ }^{0}\left(\Delta \vec{G}_{A}{ }^{\text {th }}\right)_{C}{ }^{*}-\bar{V}_{A}\left(X_{B}{ }^{0} \bar{V}_{B}+X_{C}{ }^{0} \bar{V}_{C}\right)^{-1} \Delta \bar{G}_{B C}{ }^{\text {th }}\right]
\end{aligned}
$$

\begin{tabular}{|c|c|c|c|c|c|}
\hline \multirow{2}{*}{$\begin{array}{l}\text { solvent }(B)+ \\
\text { solvent }(C)\end{array}$} & \multirow[b]{2}{*}{$X_{\mathrm{B}}{ }^{0}$} & \multirow[b]{2}{*}{$X_{\mathrm{A}}^{\text {sat }}$} & \multicolumn{3}{|c|}{$\begin{array}{c}\% \text { dev of calcd } \\
\text { values }^{a}\end{array}$} \\
\hline & & & (2) & (3) & (4) \\
\hline \multirow{7}{*}{$\begin{array}{l}n \text {-hexane }+ \\
\text { dibutyl ether }\end{array}$} & 0.0000 & 0.003609 & & & \\
\hline & 0.2515 & 0.002944 & -4.7 & -0.1 & -0.1 \\
\hline & 0.4505 & 0.002453 & -6.8 & -0.3 & -0.3 \\
\hline & 0.5676 & 0.002177 & -7.1 & -0.3 & -0.3 \\
\hline & 0.6493 & 0.001989 & -6.6 & -0.2 & -0.2 \\
\hline & 0.8402 & 0.001571 & -3.5 & 0.6 & 0.6 \\
\hline & 1.0000 & 0.001273 & & & \\
\hline \multirow{7}{*}{$\begin{array}{l}\text { cyclohexane }+ \\
\text { dibutyl ether }\end{array}$} & 0.0000 & 0.003609 & & & \\
\hline & 0.2869 & 0.003066 & -7.1 & -0.2 & -0.1 \\
\hline & 0.5080 & 0.002647 & -10.8 & -1.4 & -1.1 \\
\hline & 0.6074 & 0.002435 & -10.9 & -1.4 & -1.1 \\
\hline & 0.7032 & 0.002230 & -10.3 & -1.6 & -1.2 \\
\hline & 0.8577 & 0.001884 & -6.8 & -1.2 & -1.0 \\
\hline & 1.0000 & 0.001551 & & & \\
\hline \multirow{7}{*}{$\begin{array}{l}n \text {-heptane }+ \\
\text { dibutyl ether }\end{array}$} & 0.0000 & 0.003609 & & & \\
\hline & 0.2330 & 0.003091 & -3.6 & -1.6 & -1.6 \\
\hline & 0.4186 & 0.002676 & -4.5 & -1.7 & -1.7 \\
\hline & 0.5379 & 0.002447 & -5.5 & -2.5 & -2.5 \\
\hline & 0.6243 & 0.002258 & -4.7 & -1.8 & -1.8 \\
\hline & 0.8130 & 0.001894 & -3.0 & -1.1 & -1.1 \\
\hline & 1.0000 & 0.001568 & & & \\
\hline \multirow{7}{*}{$\begin{array}{l}\text { methylcyclohexane + } \\
\text { dibutyl ether }\end{array}$} & 0.0000 & 0.003609 & & & \\
\hline & 0.2544 & 0.003122 & -4.8 & -0.9 & -0.9 \\
\hline & 0.4391 & 0.002799 & -8.1 & -2.8 & -2.8 \\
\hline & 0.5727 & 0.002520 & -8.0 & -2.5 & -2.5 \\
\hline & 0.6674 & 0.002315 & -7.0 & -1.8 & -1.8 \\
\hline & 0.8201 & 0.002021 & -5.6 & -1.9 & -1.9 \\
\hline & 1.0000 & 0.001652 & & & \\
\hline \multirow{7}{*}{$\begin{array}{l}n \text {-octane }+ \\
\text { dibutyl ether }\end{array}$} & 0.0000 & 0.003609 & & & \\
\hline & 0.2167 & 0.003185 & -1.9 & -1.5 & -1.5 \\
\hline & 0.4059 & 0.002837 & -3.0 & -2.4 & -2.4 \\
\hline & 0.5116 & 0.002652 & -3.4 & -2.7 & -2.7 \\
\hline & 0.6030 & 0.002478 & -2.8 & -2.2 & -2.2 \\
\hline & 0.7914 & 0.002151 & -1.5 & -1.0 & -1.0 \\
\hline & 1.0000 & 0.001836 & & & \\
\hline \multirow{7}{*}{$\begin{array}{l}\text { isooctane }+ \\
\text { dibutyl ether }\end{array}$} & 0.0000 & 0.003609 & & & \\
\hline & 0.2142 & 0.002942 & -1.8 & -1.7 & -1.7 \\
\hline & 0.4073 & 0.002391 & -2.9 & -2.7 & -2.7 \\
\hline & 0.5008 & 0.002146 & -3.2 & -3.1 & -3.1 \\
\hline & 0.6114 & 0.001860 & -2.7 & -2.5 & -2.5 \\
\hline & 0.7886 & 0.001469 & -2.3 & -2.2 & -2.2 \\
\hline & 1.0000 & 0.001067 & & & \\
\hline \multirow{7}{*}{$\begin{array}{l}\text { cyclooctane }+ \\
\text { dibutyl ether }\end{array}$} & 0.0000 & 0.003609 & & & \\
\hline & 0.2387 & 0.003481 & -5.2 & -3.5 & -3.5 \\
\hline & 0.4663 & 0.003242 & -7.7 & -5.1 & -5.1 \\
\hline & 0.5512 & 0.003114 & -7.6 & -4.9 & -4.9 \\
\hline & 0.6522 & 0.002961 & -7.6 & -5.0 & -5.0 \\
\hline & 0.8273 & 0.002653 & -6.1 & -4.2 & -4.2 \\
\hline & 1.0000 & 0.002251 & & & \\
\hline
\end{tabular}

Table I. Comparison of Predicted and Experimental Anthracene Solubilities in Several Binary Solvent Mixtures at $25^{\circ} \mathrm{C}$

Equations 2 and 3 are based on Raoult's law and eq 4 is based on the Flory-Huggins model. In the above expressions $a_{A}{ }^{\text {solld }}$ is the activity of the solid solute relative to the pure subcooled liquid, $X_{1}$ is mole fraction, and $\phi_{1}$ is volume fraction. Binary solvent properties $\Delta \bar{G}_{\mathrm{BC}}{ }^{\text {ex }}$ and $\Delta \bar{G}_{\mathrm{BC}}{ }^{\text {m }}$ refer to the excess Gibbs free energies relative to Raoult's law and the Flory-Huggins model, respectively. Solubility data measured in each pure solvent can be used to calculate the excess partial molar Gibbs free energy of the solute $\left(\Delta \bar{G}_{A}{ }^{\theta x}\right)_{i}^{*}$ and $\left(\Delta \bar{G}_{A}{ }^{\text {th }}\right)_{1}^{*}$. These quantities are then combined with the free energy of the binary solvent mixture to predict solubility in mixed solvents.

To date, testing of the limitations and applications of the NIBS model has been restricted to binary solvent systems for which experimental $\Delta \bar{G}_{\mathrm{BC}}{ }^{\text {ex }}$ values could be found in the literature. There are a number of systems, such as binary dibutyl ether + alkane systems, that have not been studied thermodynamically. Excess Gibbs free energies of such systems can 
Table II. Properties Used in the NIBS Predictions

\begin{tabular}{lcc}
\multicolumn{1}{c}{ component (i) } & $\bar{V}_{\mathrm{i}}, \mathrm{cm}^{3} / \mathrm{mol}$ & $\delta_{\mathrm{i}}{ }^{a}\left(\mathrm{cal} / \mathrm{cm}^{3}\right)^{1 / 2}$ \\
\hline$n$-hexane & 131.51 & 7.27 \\
$n$-heptane & 147.48 & 7.50 \\
$n$-octane & 163.46 & 7.54 \\
cyclohexane & 108.76 & 8.19 \\
cyclooctane & 134.88 & $8.51^{b}$ \\
dibutyl ether & 170.41 & 7.76 \\
isooctane & 166.09 & 6.86 \\
methylcyclohexane & 128.32 & $7.83^{c}$ \\
anthracene & $150.00^{d}$ & $0.01049^{e}$
\end{tabular}

${ }^{a}$ Unless otherwise noted, solubility parameters are taken from ref 9. ${ }^{b}$ Calculated from the calorimetric data from ref 10. ${ }^{c}$ Calculated from data in ref 11 . $^{d}$ Value from ref 7 . $^{e}$ Value of $a_{\mathrm{A}}$ solid from ref 7 .

be estimated from the Scatchard-Hildebrand solubility parameter model

$$
\Delta \bar{G}_{B C}{ }^{\mathrm{ex}}=\phi_{B}{ }^{0} \phi_{C}{ }^{0}\left(X_{B}{ }^{0} \bar{V}_{B}+x_{C}{ }^{0} \bar{V}_{C}\right)\left(\delta_{B}-\delta_{C}\right)^{2}
$$

where $\delta_{1}$ refers to the solubility parameter of component $i$.

Comparisons between experimental and predicted anthracene solubilities are tabulated in the last three columns of Table I. Solvent properties used in the NIBS predictions are listed in Table II. In general, eq 3 and 4 are comparable with identical overall average deviations of $2.1 \%$ and are superior to eq 2 which has an overall average $(\mathrm{rms})$ deviation of $5.5 \%$. More importantly, deviations for eq 3 and 4 fall almost within the experimental uncertainty of $1 \%$. This indicates that approximation of dibutyl ether + alkane $\Delta \bar{G}_{B C}{ }^{e x}$ values via eq 5 introduces only a relatively small error in the NIBS predictions and makes possible the calculation of presumed solute-dibutyl ether association constants from future solubility measurements.

\section{Glossary}

$a_{A}{ }^{\text {solld }}$ activity of the solid solute, defined as the ratio of the fugacity of the solid to the fugacity of the pure subcooled liquid

$\left(\Delta \bar{G}_{A}{ }^{e x}\right)^{*}$ partial molar Gibbs free energy of the solute (Raoult's law), extrapolated back to infinite dilution
$\left(\Delta \bar{G}_{A}{ }^{\text {th }}\right)^{*}$ partial molar Gibbs free energy of the solute (FloryHuggins model), extrapolated back to infinite dilution

$\Delta \bar{G}_{\mathrm{BC}}{ }^{\text {ex }}$ excess Gibbs free energy of the binary solvent mixture based on Raoult's law

$\Delta \bar{G}_{\mathrm{BC}}^{\text {fh }}$ excess Glbbs free energy of the binary solvent mlxture based on Flory-Huggins model, calculated from $\Delta \bar{G}_{B C}{ }^{\text {ex }}$ values as $\Delta \bar{G}_{B C}{ }^{\text {th }}=\Delta \bar{G}_{B C}{ }^{\text {ex }}+R T[\mathrm{ln}$ $\left.\left(X_{B}{ }^{0} \bar{V}_{B}+X_{C}{ }^{0} \bar{V}_{C}\right)-X_{B}{ }^{0} \ln \bar{V}_{B}-X_{C}{ }^{0} \ln \bar{V}_{C}\right]$

$\bar{V}_{1} \quad$ molar volume of component $\mathrm{i}$

$X_{B}{ }^{0}, X_{C}{ }^{0}$ mole fraction compositions of solvent mixture, calculated as if the solute were not present

$X_{A}{ }^{\text {sat }}$ mole fraction solubility of solute

$\phi_{\mathrm{B}}^{0}$, ideal volume fraction composition of the solvent $\phi_{c}{ }^{0}$ mixture, calculated as if the solute were not present

$\phi_{A}{ }^{\text {sat }}$ ideal volume fraction solubility of solute

$\delta_{1} \quad$ solubility parameter of component $\mathrm{i}$

rms $\quad\left(100 / N^{1 / 2}\right)\left\{\sum^{N}\left[\ln \left(X_{\text {calod }}^{\text {sat } /} / X_{\text {expt }}^{\text {sat }}\right)\right]^{2}\right\}^{1 / 2}, \%$ devia-

tion

Regletry No. Anthracene, 120-12-7; dibutyl ether, 142-96-1; hexane, 110-54-3; cyclohexane, 110-82-7; heptane, 142-82-5; methylcyclohexane, 108-87-2; octane, 111-65-9; isooctane, 540-84-1; cyclooctane, 292-64-8.

\section{Lherature Clted}

(1) Acree, W. E., Jr.; Bertrand, G. L. J. Phys . Chem. 1977, 81, 1170-3.

(2) Acree, W. E., Jr.; Bertrand, G. L. J. Phys. Chem. 1979, 83, 2355-8.

(3) Acree, W. E., Jr.; Bertrand, G. L. J. Pharm. Sci. 1981, 70, 1033-6.

(4) Acree, W. E., Jr.; Bertrand, G. L. J. Solution Chem. 1983, 12 , 101-13.

(5) Acree, W. E., Jr.; Rytting, J. H. J. Pharm. Sci. 1982, 71, 201-5.

(6) Acree, W. E., Jr.; Rytting, J. H. Int. J. Pharm. 1982, 10, 231-8.

(7) Acree, W. E., Jr.; Rytting, J. H. J. Pharm Sci. 1983, 72, 292-6.

(8) Acree, W. E., Jr.; McHan, D. R.; Rytting, J. H. J. Pharm. Scl. 1983, $72,929-34$

(9) Hoy, K. L. J. Paint Technol. 1970, 42, 76-118.

(10) Cox, J. D.; Pilcher, G. Thermochemistry of Organic and Organometallic Compounds; Academic: New York, 1970.

(11) Majer, V.; Svoboda, V.; Hala, S.; Pick, J. Collect. Czech. Chem Commun. 1979, 44, 637-51.

Received for review July 31, 1986. Accepted March 24, 1987. Acknowtedgment is made to the Donors of The Petroleum Research Fund, administered by the American Chemical Soclety, for partial support of this research.

\title{
Thermodynamic and Spectroscopic Properties of 2-Pyrrolidinones. 1. Excess Molar Volumes of 2-Pyrrolidinone + Dichloromethane, + Dimethyl Sulfoxide, + Acetone, + 2-Propanol, and + Water
}

\author{
Pälvi L. Pirllä-Honkanen and Pirkko A. Ruostesuo* \\ Department of Chemistry, University of Oulu, 90570 Oulu, Finland
}

\begin{abstract}
Negative excess molar volumes were measured for the binary llquid mixtures of 2-pyrrolldinone with acetone, dimethyl sulfoxide, dlchloromethane, 2-propanol, and water at 303.15 and $323.15 \mathrm{~K}$ over the entire composition range. The results are discussed in terms of the possible Interactions between like and unllke molecules.
\end{abstract}

\section{Introduction}

As part of a study on thermodynamic and physical properties of binary liquid mixtures containing amide as one of the com- ponents, we report here the excess molar volumes for five 2-pyrrolidinone liquid mixtures. Excess molar volumes at 303.15 and $323.15 \mathrm{~K}$ have earlier been measured for $\mathrm{N}$-methylmethanesulfinamide, $N, N$-dimethylmethanesulfinamide, $N, N$ dimethylbenzenesulfinamide, and dimethyl sulfoxide with the solvents carbon tetrachloride, 1,4-dioxane, and benzyl alcohol, and the molecular interactions in these systems have been discussed (1-3). The systems have been selected with a view to studying the molecular interactions occurring in binary mixtures of N-monosubstituted and $\mathrm{N}, \mathrm{N}$-disubstituted sulfinamides and related sulfoxides (e.g. dimethyl sulfoxide) as one compo- 